\title{
A New Generator for Tsunami Wave Generation
}

\author{
Tetsuya Hiraishi ${ }^{1}$, Ryokei Azuma ${ }^{1}$, Nobuhito Mori ${ }^{2}$, Toshihiro Yasuda ${ }^{2}$ and Hajime Mase ${ }^{2}$ \\ 1. Disaster Prevention Research Institute, Kyoto University, Kyoto 612-8235, Japan \\ 2. Disaster Prevention Researtch Institute, Kyoto University, Uji 611-0011, Japan
}

Received: January 29, 2016 / Accepted: February 17, 2016 / Published: March 31, 2016.

\begin{abstract}
A middle size experiental wave generator has been implemented is the Ujikawa Open Laboratory, Disaster Prevention Research Institute, Kyoto University. The generator is composed of a pistontype wave maker, a head strage water tank and a current generator to mainly reproduce long waves like tsunami and storm surge. The paper desribes several experimental series to predict the applicability of the generator to model tests. The three operating sysemes are capable to be controlled in one operating sysytem and start time is contorolled separately according with the target tsunami and storm surge profiles. A sharp tsunami profile is reproduced in adjusting the start timing of piston type wave maker and opening gates of head storage tunk. Any type of tsunami waves are reproduced in the generator and it becomes a storong tool to predict the effective of "resiliency" of hardwares.
\end{abstract}

Key words: Tsunami, storm surge, experimental generator tool, wave maker.

\section{Introduction}

The 2011 Tohoku Pacific off great earthquake tsunami caused the worst hazard in the Northern Japanese coastline. The various numerical simulation and field survey have revealed the tsunami height distribution at each devastated areas. However, the detail mechanism of several building collapses and turning down of coastal tidal walls has not yet clearly discussed mainly because of the unknown transformation of tsunami in shallow waters and run-up grounds.

In 2013, typhoon No.13 also caused the large storm surge mainly in the middle parts of Philippines. The run-up storm surge waves are transformed to "bore" and give impulsive force to the coastal structures. However the detail profile of the impulsive force is not revealed. The physical study using experimental instruments often become the useful tools to study on the tsunami run-up phenomena, impulsive force due to bore and surging wave force induced in storm surges. Meanwhile, the experimental results are necessary to determine the several coefficients in numerical models

Corresponding author: Tetsuya Hiraishi, professor, research field: coastal sedimentation. like friction factors. The verification of numerical modelling can be carried out by using the experimental data.

A middle size experimental wave flume has been implemented in the Ujikawa Laboratory, Disaster Prevention Research Institute, Kyoto University. Fig. 1 shows a bird-eye view of the flume. In the flume, the following three generators are equipped to reproduce the tsunami and storm surge waves in shallow water and after run-up:

(1) flume size: $45 \mathrm{~m} \times 4 \mathrm{~m} \times 0.8 \mathrm{~m}$ (side wall height is $2 \mathrm{~m}$ ) with water tank ( $1 \mathrm{~m}$ deep);

(2) piston type wave generator with $2.5 \mathrm{~m}$ stroke;

(3) current generator (the maximum $0.8 \mathrm{~m}^{3} / \mathrm{s}$ );

(4) water storage tank over wave generator $\left(4 \mathrm{~m}^{3}\right)$.

We conducted several fundamental tests using the new flume and generated an impulsive wave with a sharp peak. The newly developed wave flume in our laboratory will be demonstrated in the final paper.

\section{Experimental Method}

The eight wave gages are implemented to measure the variation of wave profile. The position of wave gages is expressed in Fig. 2. Table 1 shows the 


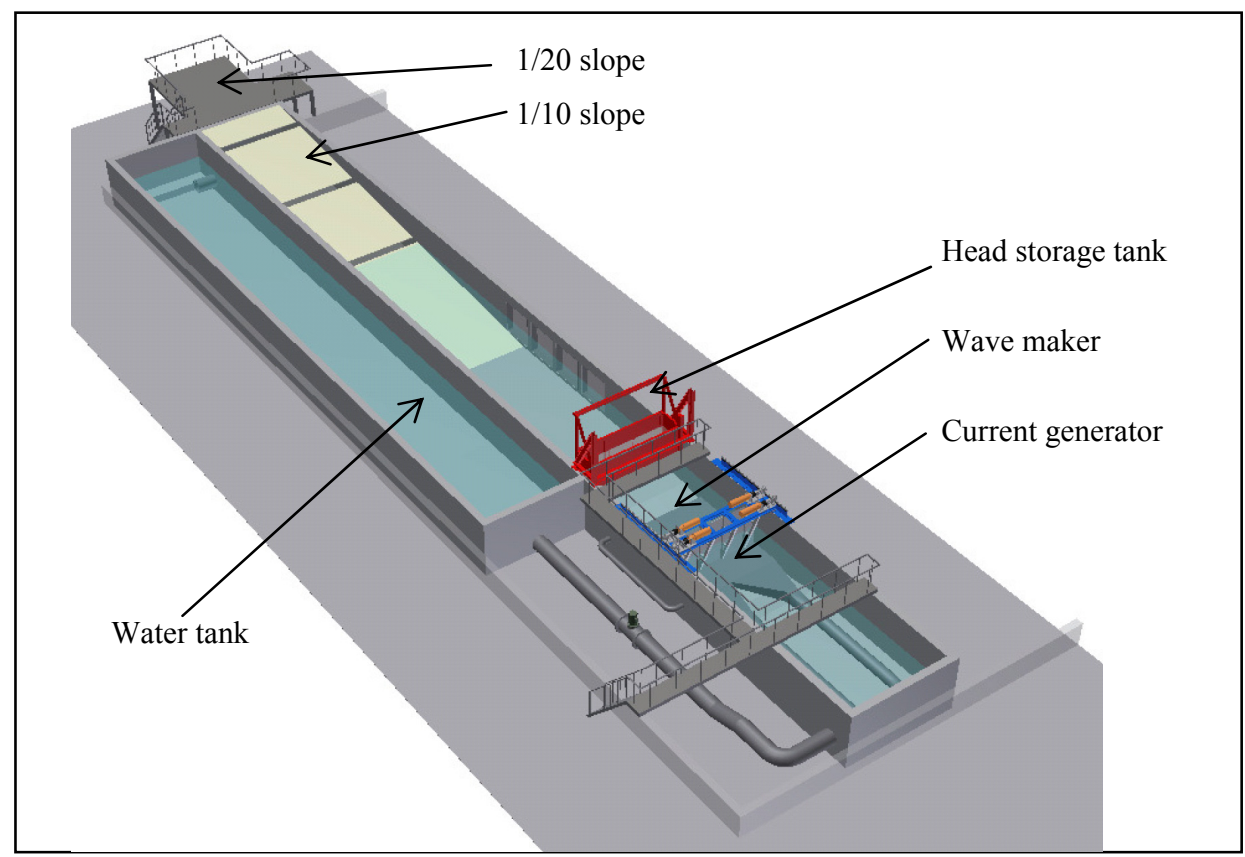

Fig. 1 Bird view of new experimental basin.
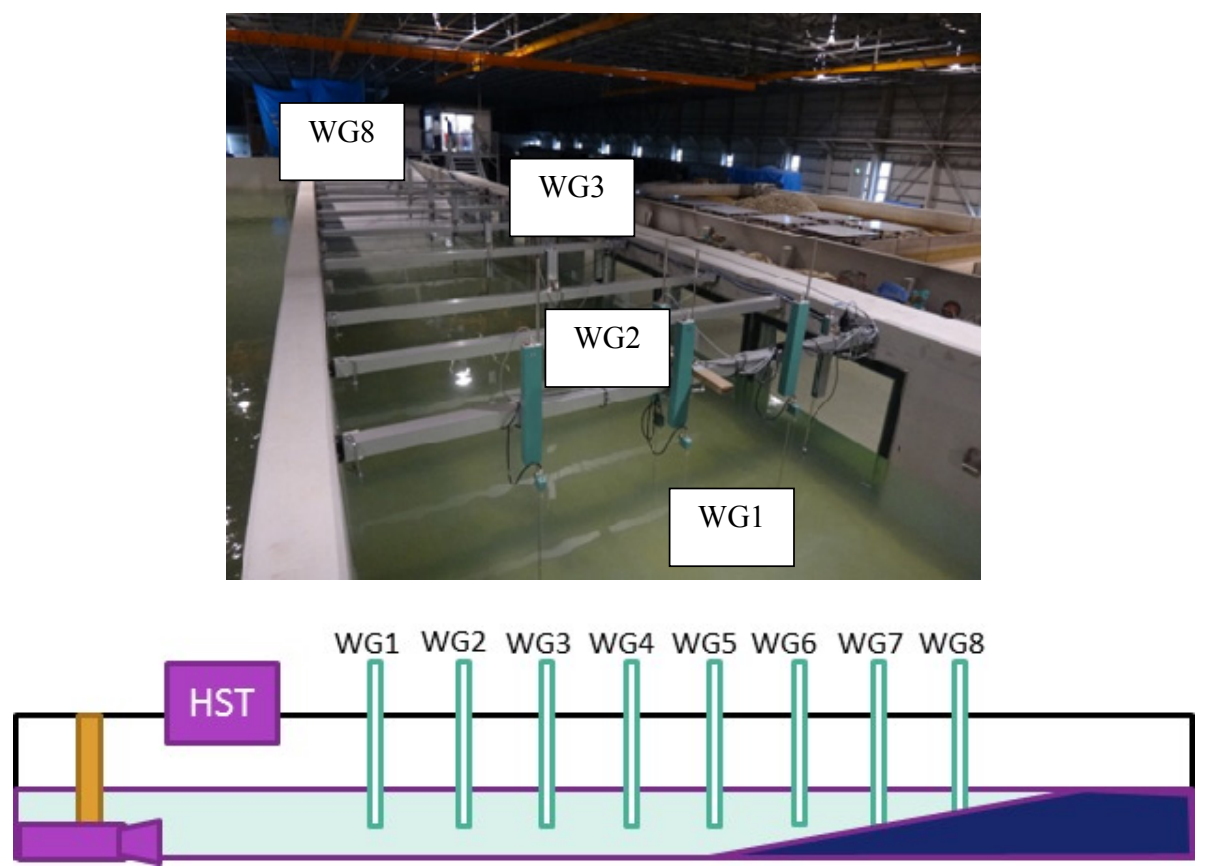

Fig. 2 Position of wave gage.

Table 1 Experimental case for piston wave maker.

\begin{tabular}{lll}
\hline Exp. no. & Wave height $(\mathrm{cm})$ & Water depth $(\mathrm{cm})$ \\
\hline Trial 1 & 10 & 80 \\
Trial 2 & 20 & 80 \\
Trial 3 & 30 & 80 \\
Trial 4 & 40 & 80 \\
Trial 5 & 50 & 80 \\
\hline
\end{tabular}




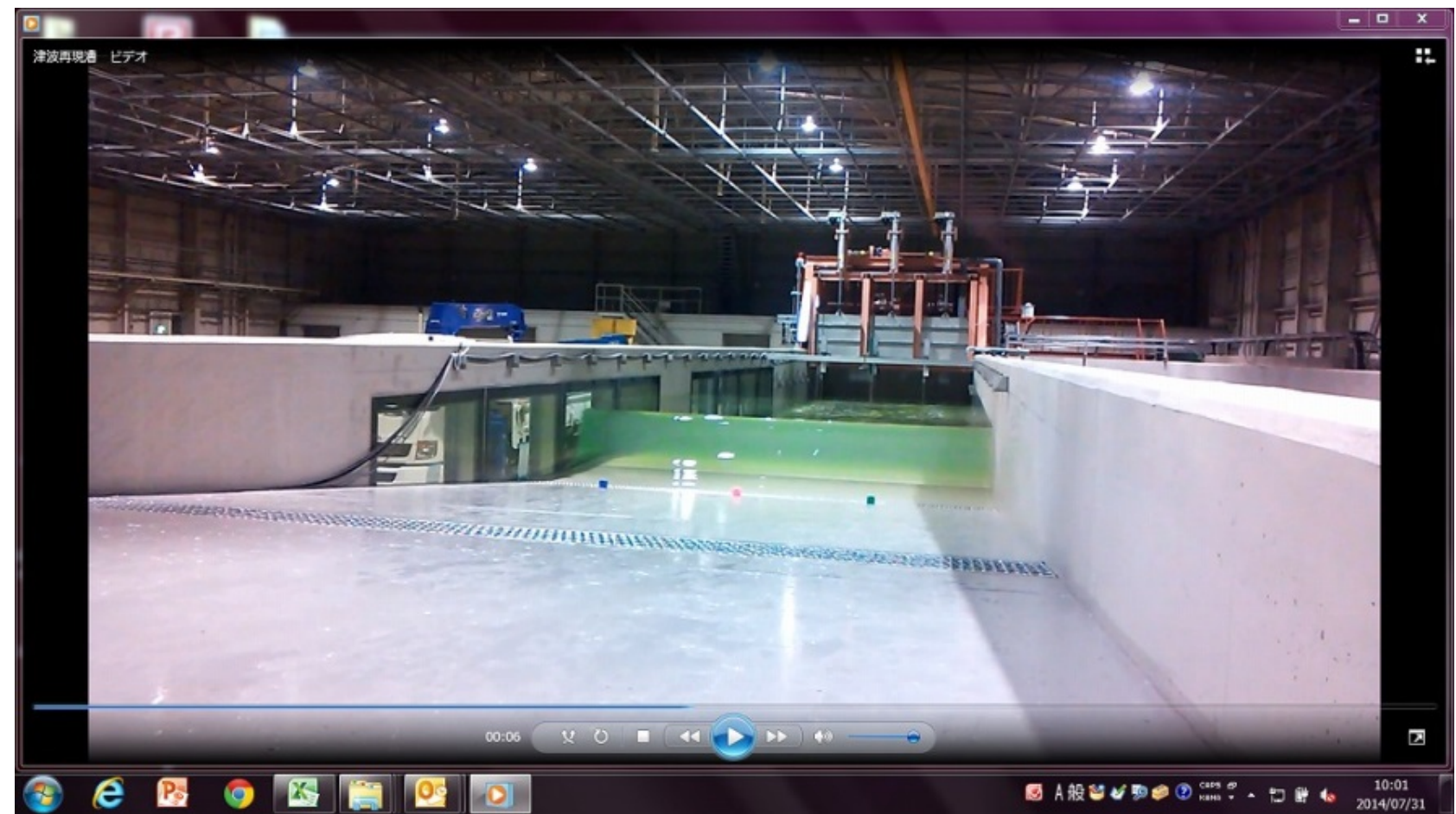

Photograph 1 Generation tsunami (soliton) wave.

experimental case using the wave maker. As shown in Table 1, the water depth is constant and $80 \mathrm{~cm}$. Target wave height varies from $10 \mathrm{~cm}$ to $55 \mathrm{~cm}$. In each case, two trial was carried out to check the uniformity of experimental results. Photograph 1 shows the generation of one peaky wave generated in the piston type wave generator. The wave paddle is removed to the backside slowly as not to generate waves in the wave basin. A large wave is generated in removing the paddle to the front direction in a short time.

Fig. 3 shows a tsunami wave profile obtained at the offshore observation point [1] $20 \mathrm{~km}$ far from the coast line. High peaky wave is observed at the initial time. This profile is obtained in the offshore side, so the peak may become more representative in shallow water areas. The low peak with long wave succeeds. The time duration of long period tsunami wave profiles are very long. Therefore several operation modes are inevitable to reproduce such tsunami waves. High peak wave is represented in "soliton" wave in the experimental basin. In our basin, the piston type wave maker represents to the generator of soliton wave at initial stage of tsunami. The succeeding long period high water level is reproduced in the current generator. The head storage tank is also employed to reproduce the bore wave in the basin.

At the first, we studied the efficiency of piston type wave generator. Table 1 shows the experimental case for piston type wave maker test. The measurement of water level was carried out at three times for each case.

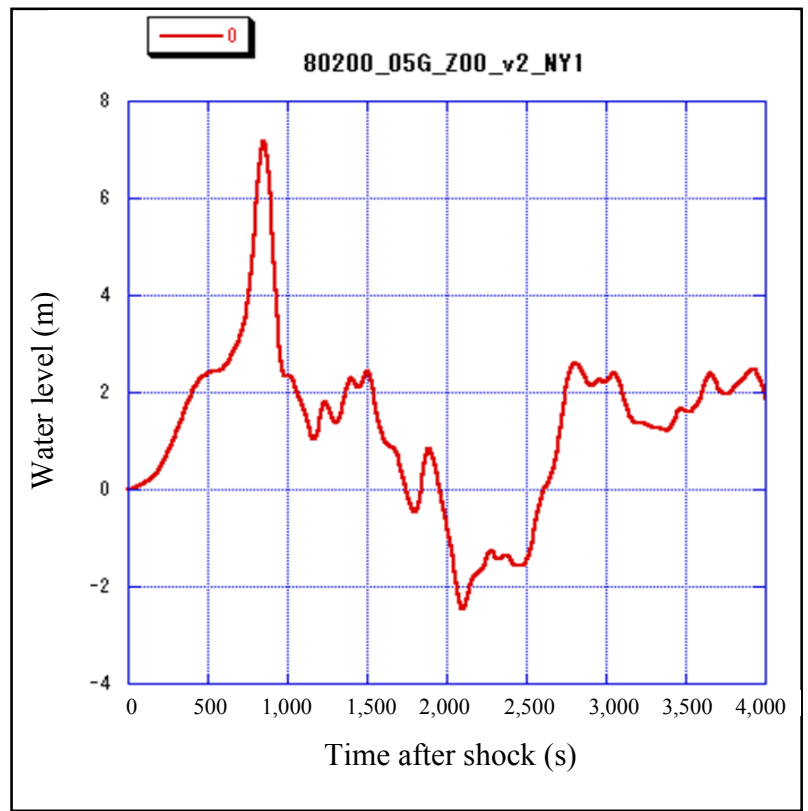

Fig. 3 Tsunami profile obtained in the offshore. 
The soliton wave is generated in such operation mode. The soliton wave profile is expressed as follows:

$$
\begin{gathered}
\zeta(X)=\operatorname{asech}^{2} \alpha x-\frac{3}{4} \frac{a^{2}}{h} \operatorname{sech}^{2} \alpha x\left(1-\operatorname{sech}^{2} \alpha x\right) \\
\alpha x=\sqrt{\frac{3}{4} \frac{a}{h}}\left(1-\frac{5}{8} \frac{a}{h}\right) \frac{X}{h} \\
X=C T \\
C=\sqrt{g h}\left[1+\frac{1}{2}\left(\frac{a}{h}\right)-\frac{3}{20}\left(\frac{a}{h}\right)^{2}\right]
\end{gathered}
$$

where, $a$-wave height, $h$-water depth, $t$-time.

Table 2 shows the experimental case for tsunami wave only generated by current generator. The system is controlled by imputing the water volume per minute. The duration is the time of pump working. In the experiment, we used the two time duration (120 s and $240 \mathrm{~s}$ ). However the water level becomes stable in $120 \mathrm{~s}$, so the cases with $120 \mathrm{~s}$ duration are introduced in the paper.

Table 3 shows the case to compare the reproduced

Table 2 Experimental case for current generator.

\begin{tabular}{lll}
\hline Exp. no. & Constant flow $\left(\mathrm{m}^{3} / \mathrm{min}\right)$ & Time duration $(\mathrm{s})$ \\
\hline Trial 6 & 0.1 & 120 \\
Trial 7 & 0.2 & 120 \\
Trial 8 & 0.3 & 120 \\
Trial 9 & 0.35 & 120 \\
Trial 10 & 0.1 & 240 \\
Trial 11 & 0.2 & 240 \\
Trial 12 & 0.3 & 240 \\
Trial 13 & 0.35 & 240 \\
\hline
\end{tabular}

Table 3 Experimental case for head storage water tank.

\begin{tabular}{clll}
\hline Exp. no. & $\begin{array}{l}\text { Tank height } \\
(\mathrm{cm})\end{array}$ & $\begin{array}{l}\text { Tank volume } \\
\left(\mathrm{m}^{3}\right)\end{array}$ & $\begin{array}{l}\text { Open height } \\
(\mathrm{cm})\end{array}$ \\
\hline Trial 14 & 50 & 0.5 & 50 \\
Trial 15 & 50 & 1.0 & 50 \\
Trial 16 & 50 & 1.5 & 50 \\
Trial 17 & 50 & 2.0 & 50 \\
Trial 18 & 50 & 2.5 & 50 \\
Trial 19 & 50 & 3.0 & 50 \\
Trial 20 & 50 & 3.5 & 50 \\
Trial 21 & 50 & 4.0 & 50 \\
\hline
\end{tabular}

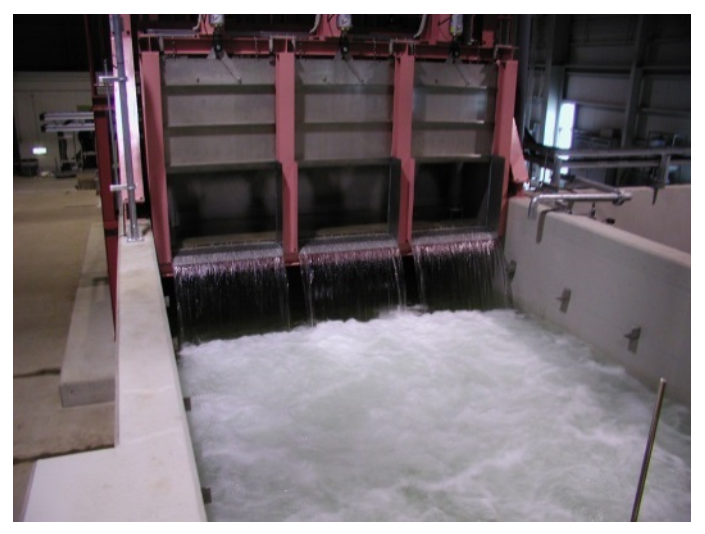

Photograph 2 Water fall from the head storage tank.

wave height in the different volumes stored in the head storage tank. The maximum volume of head storage tank is $4 \mathrm{~m}^{3}$. In the experiment, the volume was varied with constant height of opening and opening speed. Photograph 2 shows the water fall in front of the storage tank.

\section{Experimental Results}

At the first, profile of initial tsunami wave generated by the piston maker is expressed. Fig. 4 shows the theoretical soliton and practically generated wave profile. The comparison of the both profiles shows the experimental wave profile agrees well to the theoretical ones. Therefore the peaky sharp tsunami wave is capable to be reproduced a soliton wave in a piston wave maker.

Fig. 5 shows the variation of tsunami height measured at No.1 gage for input tsunami height. For each case, three measurements were done and the averaged related line was indicated. Target tsunami height is almost reproduced in inputting the same height to operation system.

Fig. 6 shows the wave height distribution along the longitude line of basin. In the flat part, in the basin tsunami height $\left(H_{\max }\right)$ is almost uniform and similar. The height becomes small at the most far point on the slope because the wave is broken on the shallow slope.

Fig. 7 shows the variation the tsunami wave height (No.1) related for the input volume data to current 


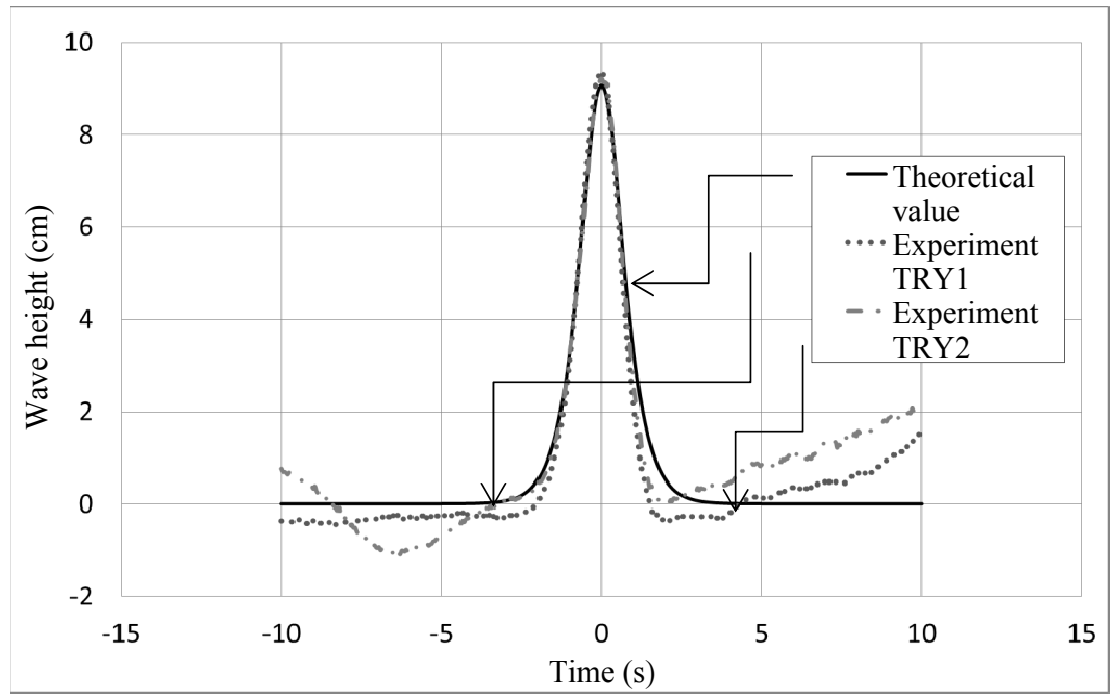

Fig. 4 Comparison of theoretical and experimental soliton wave profile.

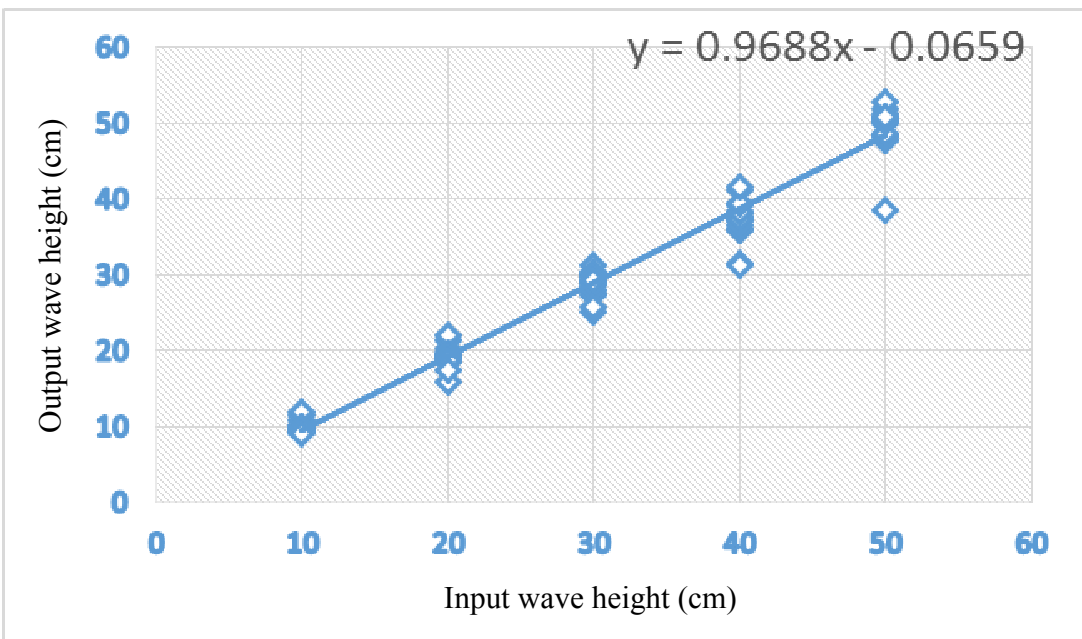

Fig. 5 Relation between the input and measured soliton wave height.

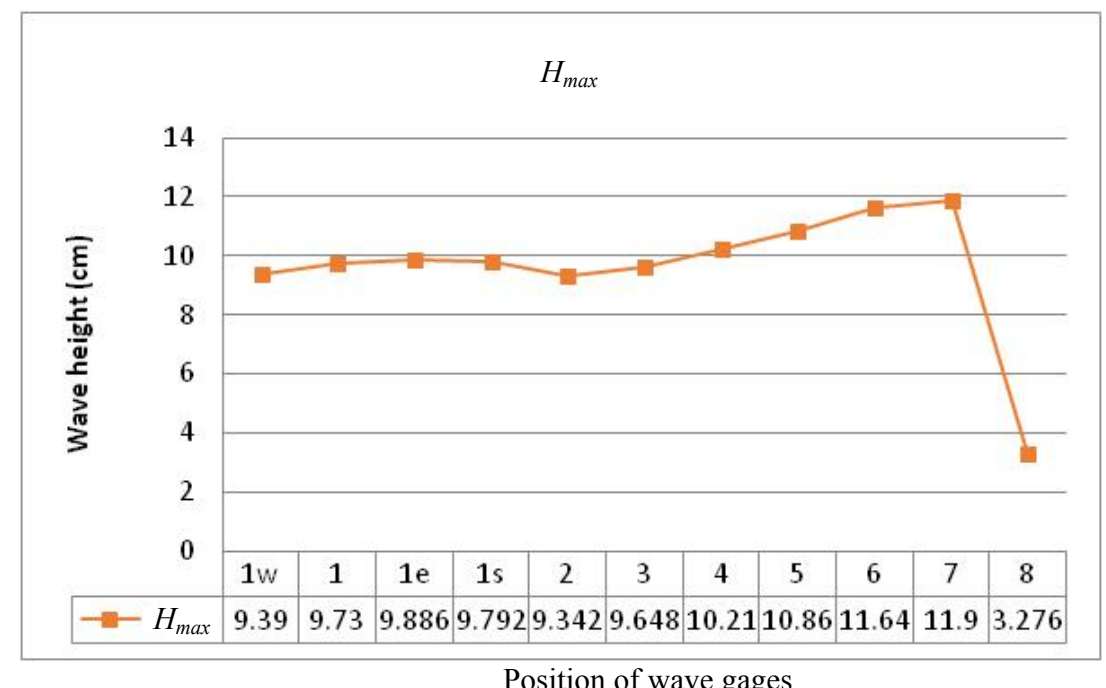

Position of wave gages

Fig. 6 Tsunami height distribution along the longitude direction in basin. 


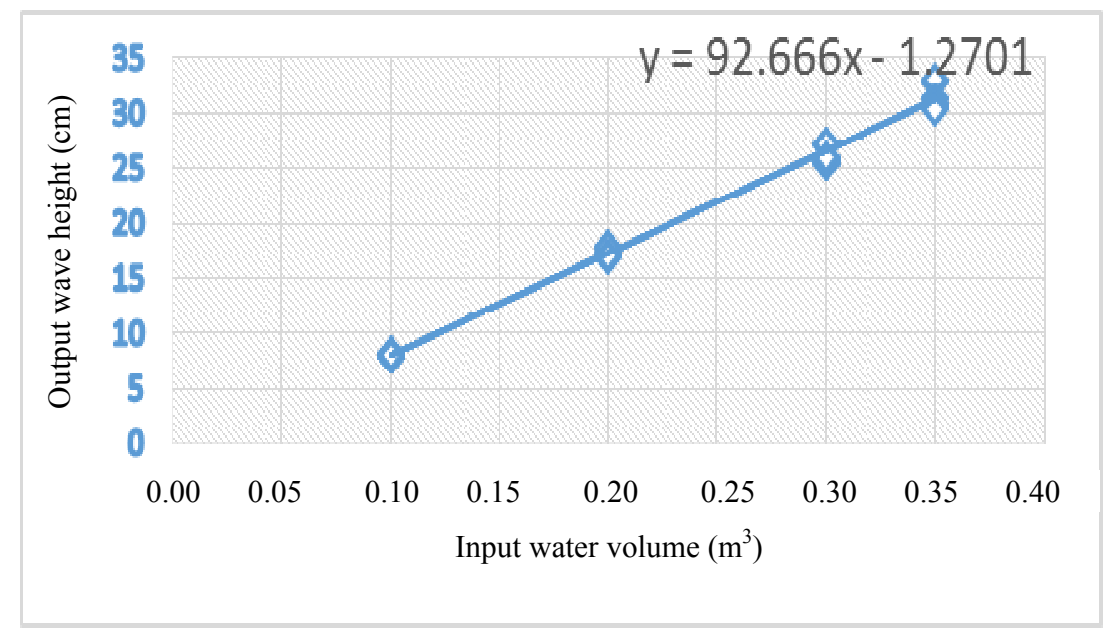

Fig. 7 Relation of generated tsunami height and storage water volume.

generator. The tsunami height linearly as the input water volume increases. The maximum tsunami height becomes about $30 \mathrm{~cm}$. Fig. 7 demonstrates the current generator is effective to reproduce tsunami wave as well the piston wave maker.

Fig. 8 shows the tsunami height variation when the head storage tank is opened. The water volume stored in the tank is shows in Table 3. The maximum water volume inside the tank is $4 \mathrm{~m}^{3}$. Fig. 8 demonstrates the tsunami wave height increase as the input water volume increases. The maximum wave height is about $20 \mathrm{~cm}$ when the maximum water volume is stored. The relation is approximately linear and the generated tsunami height is controlled in the input water tank volume.

The height of the tank and opening gate height are controlled, but the both parameters had no influences to the heights. The initial volume of the tank was main parameter to determine the generated wave height.

The characteristic of the newly developed basin is capability to operate the three generators (piston maker, current generator, head tank). Fig. 9a shows the one example of generated tsunami profile using the three operation modes. The initial two peaks the sharp tsunami profiles generated the piston maker and head tank. The operation timing is also controlled and the peaks of tsunami are capable to be occurred at the same time. Fig. $9 \mathrm{~b}$ shows the tsunami profile when the tsunami peak generated wave maker and that generated in head tank appear at the same time. The peak height becomes much higher than that induced by one operation tool. The composing of the three operation modes is applicable to any tsunami profile observed and simulated in the target area.

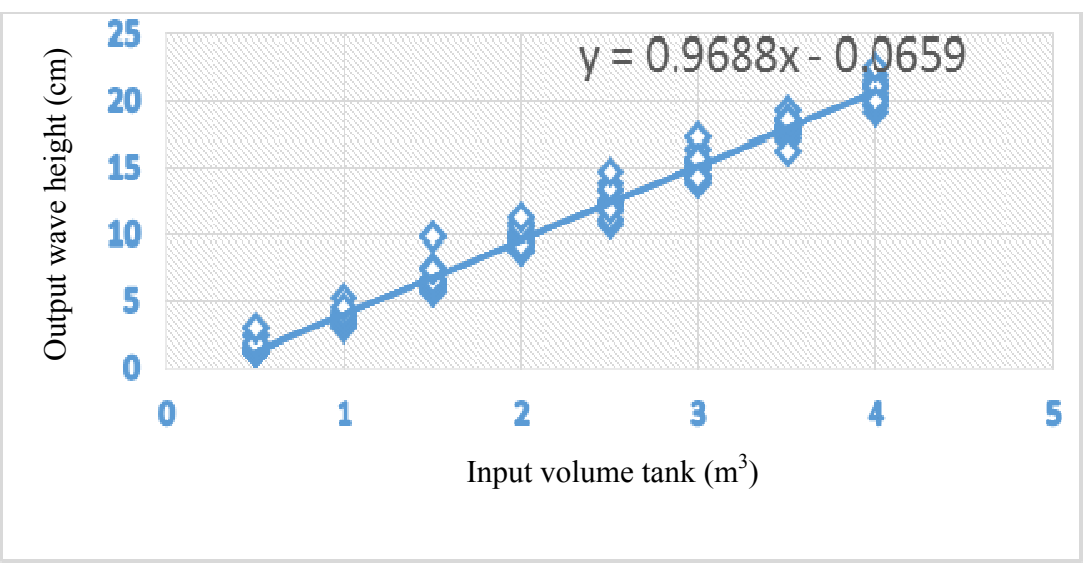

Fig. 8 Relation of tsunami height and water volume in head tank. 


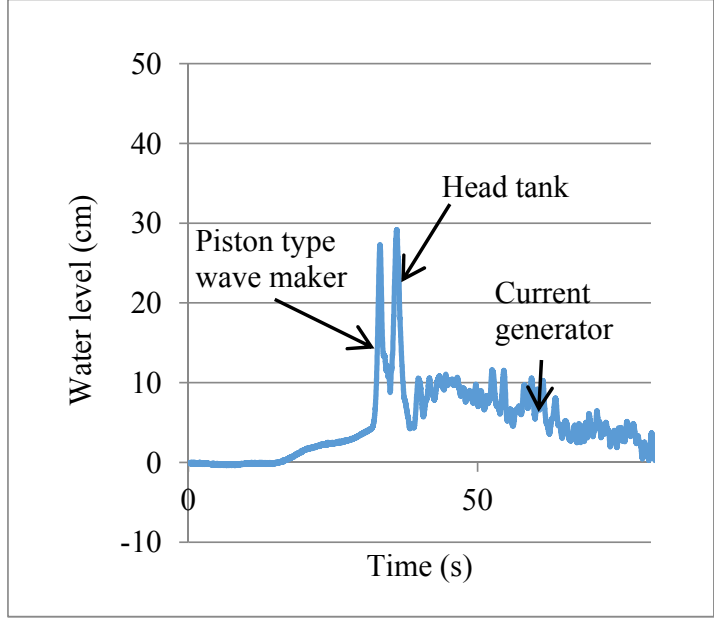

(a) Separate generation

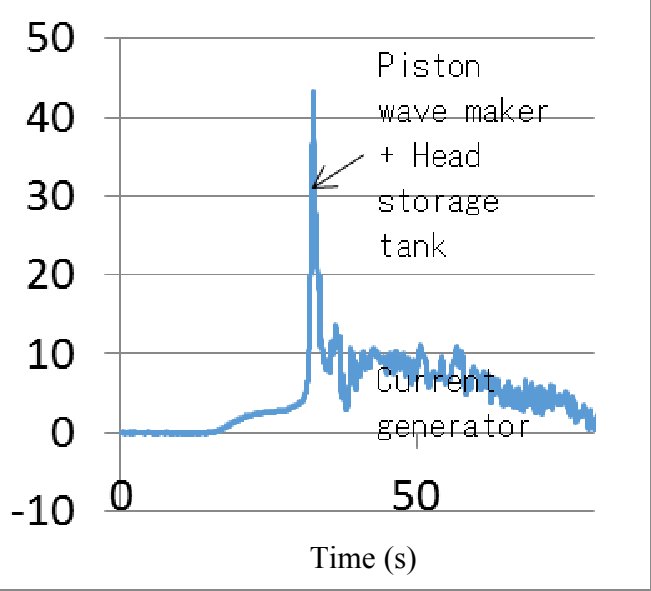

(b) Timing adjustment operation

Fig. 9 Applicability of generation for any type of tsunami profile.

\section{Conclusions}

The following conclusions are derived in the paper:

(1) A new tsunami and storm surge reproduction basin has been developed with the three operation mode;

(2) Soliton wave expressing the peaky tsunami profile is reproduced in the piston wave maker;

(3) Current volume and water volume in the head storage tank determine the reproduced tsunami height;

(4) The higher peak tsunami wave profile can be reproduced by adjusting the operation timing.

\section{Reference}

[1] Takahashi, S. 2011. "Urgent Survey for 2011 Great East Japan Earthquake and Tsunami Disaster in Ports and Coasts." Technical Note of the Port and Airport Research Institute. 